\title{
Off-Line Field Diagnostics for MV and HV Oil-Paper Insulated Cables
}

\author{
Sarajit Banerjee, Ali Naderian \\ Kinectrics Inc., Toronto, Canada
}

\author{
Howard Sedding \\ Iris Power - Qualitrol LLC
}

\begin{abstract}
Focusing on off-line electrical diagnostics this paper presents a technical approach, including acceptance criteria options, for in-situ field condition assessment of MV paper insulated lead covered (PILC) cable and HV/EHV self-contained fluid-filled (SCFF) cables. The proposed approach consists of a combination of off-line AC Hipot, partial discharge (PD) measurement and frequency domain dielectric spectroscopy. Case studies illustrate the successful practical application of this technical approach for diagnostics and condition assessment, including replacement prioritization or 'return to service' decisions on critical cables.
\end{abstract}

\section{Introduction}

Many of the underground transmission and distribution oil-paper insulated cables in service have reached, or will soon reach, the end of their lives. Many owners and utilities are alerted to the possibility of the mortality of their impregnated paper-insulated cables and require information on remaining service life.

There is some existing guidance regarding field and laboratory condition assessment methods from CIGRE [1] and IEEE [2,3,4], and a CIGRE Working Group is updating the status on diagnostic test methods in use for AC self-contained fluid-filled (SCFF) cables [5].

There is, however, limited literature discussing actual experience where a combination of applications of advanced off-line in-situ field diagnostic techniques have been utilized to undertake condition assessment, replacement prioritization or 'return to service' decisions on critical cables. It is critical that owners develop a reliable method for periodically assessing the condition of their cable systems, allowing for corrective action before catastrophic failures.

Focusing on off-line on-site electrical diagnostics, this paper presents the merits of using a technical approach, including acceptance criteria options, for in-situ field condition assessment of MV and HV PILC and SCFF oil filled cables. It also discusses case studies including:

- Off-line partial discharge under near power frequency $(20-300 \mathrm{~Hz})$ conditions, using traditional and wide-band electrical PD measurement

- Dielectric spectroscopy testing

\section{Field Testing of PILC and SCFF Cables}

\subsection{Hipot Test and Leakage Current Test}

DC Hipot testing has been traditionally used for acceptance and maintenance of MV and HV oil filled cables. This test is used to for identification of gross defects / 'weak points' in the impregnated paper insulation. During this test, the leakage current of the cable as well as the applied voltage is monitored. The cable failure is typically preceded by a sudden change in the leakage current. IEEE 400.1 and IEC 60414 cover the test method and acceptance criteria for different cable systems $[4,6]$.

As a general rule, for existing cables, the highest value of maintenance DC Hipot should not exceed $60 \%$ of the final factory test level. The voltage can gradually increase to the specific value and maintain for 15 minutes.

DC Hipot testing is not sufficient to perform condition assessment, or replacement prioritization. Leakage current readings could have wide variations due to the atmospheric conditions, and lack of control of leakage currents / charge distributions at terminations.

\subsection{AC Hipot and Partial Discharge Test}

Oil-paper insulated cables and their accessories, can tolerate higher PD for a long time due to the high PD resistance of impregnated paper, compared with polymeric cables. Typical partial discharge sources in fluid-impregnated cables are [7]:

$\begin{array}{ll}\text { - } & \text { Dry or cracked paper } \\ \text { - } & \text { Loss of oil leading to voids } \\ \text { - } & \text { Voids due to poor impregnation } \\ \text { - } & \text { Installation errors of terminations or joints }\end{array}$

In MV class belted cables, where the cores are not individually screened, the area between the three cores becomes a high risk for deterioration due to PD [7]. This can happen particularly during heavy loading, which may cause core separation. Another problem with belted cable at higher voltages is the high tangential stress causing discharge activity between the layers, finally resulting in a failure 
AC test voltage can create the closest condition to the cable operating condition in terms of electric field distribution, surface charge, space charge, and the number of zero crossings of the voltage, especially when compared to DC test voltage. The AC Hipot in itself can be applied (i.e. as a stand-alone pass/fail test) as an assessment of relatively severe bulk degradation in an aged PILC or SCFF cable system; however, it is not considered as a diagnostic test, and may be destructive on a degraded/highly aged cable. A combination of AC Hipot and PD however (or off-line PD as a stand-alone test) is a strong diagnostic tool which can be used in aged PILC and SCFF cables to additionally identify and distinguish localized electrical defects within the cable and accessories, and establish a baseline for future trending (i.e. assess any deterioration trends being established over time).

\subsection{Time Domain Dielectric Spectroscopy (TDS)}

DS measurements in the time domain are based on the application of a DC voltage across the insulation for a specified time. The TDS data is then typically transitioned into the frequency domain using either Fourier transformation of the TD data, or the Hamon Approximation [9]. The diagnostic information that can then be gained from frequency domain dielectric response characteristics of $\tan \delta$ are further discussed in Section 2.5.

A simplified approach to analyze the time domain DS test data, in itself, is to combine both polarization and depolarization current data as conductivity factor (CF). The CF is the ratio of conductivity evaluated from the polarization and depolarization currents at 30 and 60 seconds [10].

$C F=\frac{\sigma_{30 S}}{\sigma_{60 S}}=\frac{i_{p}(30 S)-i_{d p}(30 S)}{i_{p}(60 S)-i_{d p}(60 S)}$

The advantage of CF to PI is that with CF analysis it is possible to avoid dependency of test results on:

- temperature

- $\quad$ geometry of cable

- charging voltage

\subsection{Frequency Domain Spectroscopy (FDS)}

In the frequency domain the dielectric response appears as the dissipation factor $\tan \delta$ at certain frequencies or a frequency range typically between $1 \mathrm{mHz}$ to $1000 \mathrm{~Hz}$.

In the FDS method, diagnostic parameters such as the complex capacitance $\mathbf{C}(\boldsymbol{\omega})$ and complex permittivity $\boldsymbol{\epsilon}(\boldsymbol{\omega})$ are calculated to derive dissipation factor $\tan \delta$.

$$
\tan \delta=\frac{I_{R}}{I_{C}}=\frac{C^{\prime \prime}(\omega)}{C^{\prime}(\omega)}=\frac{\varepsilon^{\prime \prime}(\omega)}{\varepsilon^{\prime}(\omega)}
$$

Moisture is one of the most common causes of deterioration of oil-impregnated paper insulation cables. Moisture can penetrate the insulation from outside due to leaks in the lead sheet but also water can be produced as a by-product of thermal aging of the cellulose, which acts as a catalyst for further aging. Intrusion of moisture into the insulation system could also directly increase leakage current, causing localized thermal runaway and eventual failure.

The moisture content of PILC cable insulation can be estimated using an empirical formula based on minimum $\tan \delta[11]$ :

$$
m c \%=15.3+2.53 \ln \left(\tan \delta_{\min }\right)
$$

Where $\tan \delta_{\min }$ is the global minimum value across the measured spectrum $(0.001 \mathrm{~Hz}$ to $1000 \mathrm{~Hz})$. However, other studies have shown that this statement may not be true for field aged oil-paper insulated cables [12]. The degradation by-products are polarized and it is hypothesized that their response may overcome the moisture response of FDS. Further research is required to understand the limitations of the empirical formulae for field aged oil-paper cables. An example of the effect of moisture on the FDS curve which is the base of the current interpretation of FDS is illustrated in Figure 1.

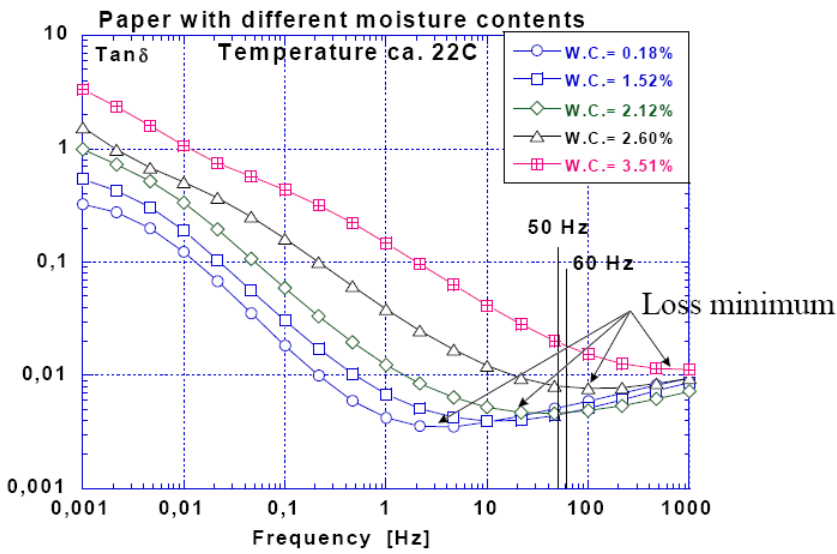

Figure 1: A baseline of DS for Kraft paper of PILC [11]

Compared with TDS, the accuracy of FDS is increased by filtering and measuring over several ac cycles at a given frequency.

\section{Proposed Technical Approach}

\subsection{AC Hipot and Partial Discharge Testing}

IEC 60141-1 provides guidance for factory acceptance testing of oil filled cables [6]. The AC Hipot level proposed by this standard is:

$2 U_{0}+10 k V$ for cables with $U_{0} \leq 87 k V$

$1.67 U_{0}+10 \mathrm{kV}$ for cables with $U_{0}>87 \mathrm{kV}$ 
The purpose of applying an over-voltage for a reasonable duration is to re-initiate PD that may have been present at operating voltage, and uncover latent (i.e. undeveloped) defects. For AC Hipot testing of $\mathrm{HV} / \mathrm{EHV}$ class fluid-filled cables, no formal guidance is provided for either after-installation acceptance or condition assessment testing. In practice, a voltage of up to approximately $1.2 \mathrm{U}_{0}$ to $1.7 \mathrm{U}_{0}$ is applied for up to 1 hour. For MV cables, the highest value of AC Hipot is typically specified to not exceed $70 \%$ of the final factory test level, and the test duration is limited to 5 minutes $[8,15]$. This level may be further reduced in practice to consider the age/condition of tested cables.

Based on extensive on-site field testing conducted by Kinectrics and its predecessors, it is proposed that an on-site PD measurement approach is based upon continuously monitoring PD during the AC Hipot test, and completing a dedicated PD test following completion of the withstand test for determination of the PD inception voltage (PDIV) and PD extinction voltage (PDEV). The PD measurements should be performed using both IEC 60270 bandwidths (conventional) and in broadband ranges (non-conventional). The latter allows for characterization of the PD behavior at higher frequencies. Furthermore, cables should ideally be tested shortly after being taken out of service, since otherwise oil may have time to penetrate through to dry, aged spots thus resulting in somewhat higher PDEV and PDIV measurements during off line tests.

If $\mathrm{PD}$ is detected and the source is determined to be internal to the cable system based on characterization of the PD behavior, the next steps are localization and condition assessment. The source(s) can be located using either acoustic/RF methods or time-of-flight principles. With regards to condition assessment, PD activity in oil-paper insulated cables is in itself not exceptional, and can be tolerated to varying degrees this is a key contrasting point compared to extruded cables. Thus if data is available, an initial condition assessment criterion for PILC or SCFF cable PD is to ensure that a deterioration trend is not being established over time. Such a trending based approach can form a primary PD assessment strategy for an oil-paper insulated cable.

Whether trending based or at a single point in time, the PDEV can form a key part of the condition assessment, along with other factors such as PD intensity, phase resolved PD patterns (PRPDs), (normalized) magnitudes, location etc. It is important that the PDEV rather than PDIV is used, since the former eliminates the effect of statistical time lag in voids. A reasonable acceptance criterion for fluid-filled cable PD tests is that the cable systems (including accessories) be free of measurable dielectric PD up to the specified PDEV.

It is notable that the evaluation of the severity of a PD source is not determined based on the measured (normalized) PD level alone for various reasons, not the least of which is that the attenuation characteristics of PILC and SCFF cables may mask the actual magnitude of the PD activity at the discharge location(s).

\subsection{Frequency Domain Spectroscopy}

The cable is subjected to frequency domain spectroscopy using a variable frequency low voltage (typically 50Vrms to $140 \mathrm{Vrms}$ ) signal generator. The test procedure consists of energizing the cable and recording data in the frequency range of $1 \mathrm{mHz}$ to $1000 \mathrm{~Hz}$. It is suggested to avoid voltages higher than a few hundred volts due to the 'Garton Effect'[13].

The results of FDS can be interpreted based on Table 1, which is a simplified version of equation 3 from [11] and includes a qualitative judgement of condition based on the measured Tan $\delta$ results and frequency response. Since the use of FDS results from field-aged cables is an evolving diagnostic technique, the data interpretation methodology in Table 1 are considered guidelines that may evolve as further field data is gained.

Table 1: Example data interpretation of DS for PILC cables

\begin{tabular}{|c|c|c|}
\hline $\begin{array}{c}\text { Minimum Power } \\
\text { Factor }\end{array}$ & $\begin{array}{c}\text { Estimated average } \\
\text { moisture [\%] }\end{array}$ & Condition \\
\hline $0.002-0.0035$ & Below 1 & Good \\
\hline $0.0035-0.0050$ & $1-2.5$ & Moderately aged \\
\hline $.005-0.01$ & $2.5-3.5$ & $\begin{array}{c}\text { Considerably } \\
\text { aged }\end{array}$ \\
\hline Above 0.01 & Above 3.5 & Bad condition \\
\hline
\end{tabular}

FDS can also potentially be employed for detecting other defects such as carbonization, oil and paper contamination, and oil starvation (dryness). IEEE is developing an FDS guide for oil-filled transformers with examples of non-moisture related defects that can theoretically be used for oil-filled cables [14].

\section{Case Studies}

\subsection{PILC}

A series of AC Hipot/PD and FDS were performed on a circuit consisting of 6 PILC cables (2 cables per phase), each approximately 27 years old, installed in a nuclear plant. The objective of the test was trending as well as diagnostic. These PILC cables were installed in a triplex configuration containing three $25 \mathrm{kV}$ rated, $350 \mathrm{MCM}$ cores, mass impregnated oil-paper insulated in a single lead sheath. The nominal line-to-ground operating voltage of the cables was $13.8 \mathrm{kV}$. The AC Hi-pot test was performed at $12 \mathrm{kVrms}$ for 5 minutes, and the PD test was performed at $8 \mathrm{kV}$, which corresponded to the line-ground operating voltage of the cable. The acceptance criteria for the AC hipot and PD testing was primarily based on Ontario Hydro Standard STD5-C-H- 
57100-0012 R0 [8,15], with some modifications to account for safety clearance limitations. The summary of test results is in Table 2. Data measured 5 years prior on the same circuit is shown in Table 3. PRPD graphs corresponding to the PD results for the phase cables A1 to C2 (from Table 2) are shown in Figures 2 to 4.

Table 2: Off-line AC Hipot and PD test results for Circuit 'A.' Reported magnitudes are based on IEC 60270 bandwidth settings.

\begin{tabular}{||c|c|c|c|c||}
\hline $\begin{array}{c}\text { Phase } \\
\text { (Cable } \\
\text { ID) }\end{array}$ & $\begin{array}{c}\text { AC Hi-Pot - } \\
\text { 12kV for 5 } \\
\text { Minutes }\end{array}$ & $\begin{array}{c}\text { PD @ 8 kV (pC) - } \\
\text { IEC 60270 }\end{array}$ & $\begin{array}{c}\text { PDIV } \\
\mathbf{( k V )}\end{array}$ & $\begin{array}{c}\text { PDEV } \\
\mathbf{( k V )}\end{array}$ \\
\hline $\mathrm{X} 1$ & Pass & 270 & 5 & 4.0 \\
\hline $\mathrm{X} 2$ & Pass & 0 & 8.7 & 8.0 \\
\hline $\mathrm{Y} 1$ & Pass & 210 & 6.4 & 5.7 \\
\hline $\mathrm{Y} 2$ & $\begin{array}{c}\text { Limited to 8kV } \\
\text { for 2 minutes }\end{array}$ & $\begin{array}{c}7000 \text { (700pC @ } \\
\text { PDIV) }\end{array}$ & 3.1 & 2.8 \\
\hline $\mathrm{Z} 1$ & Pass & 0 & 8.4 & 8.1 \\
\hline $\mathrm{Z} 2$ & Pass & 420 & 6.2 & 5.1 \\
\hline
\end{tabular}

Table 3: Original Off-line AC Hipot and PD test results for Circuit 'A,' (5 years prior to test results from Table 2) based on IEC 60270 bandwidth settings.

\begin{tabular}{|c|c|c|c|c||}
\hline $\begin{array}{c}\text { Phase } \\
\text { (Cable } \\
\text { ID) }\end{array}$ & $\begin{array}{c}\text { AC Hi-Pot - } \\
\mathbf{1 2 k V} \text { for 5 } \\
\text { Minutes }\end{array}$ & PD @ 8 kV (pC) & $\begin{array}{c}\text { PDIV } \\
\mathbf{( k V )}\end{array}$ & $\begin{array}{c}\text { PDEV } \\
\mathbf{( k V )}\end{array}$ \\
\hline $\mathrm{X} 1$ & Pass & 300 & 7.5 & 6.6 \\
\hline $\mathrm{X} 2$ & Pass & 200 & 6.8 & 6.6 \\
\hline $\mathrm{Y} 1$ & Pass & 400 (intermittent) & 7.9 & 7.3 \\
\hline Y2 & Pass & 400 & 3.9 & 3.6 \\
\hline $\mathrm{Z} 1$ & Pass & 600 (intermittent) & 7.9 & 7.5 \\
\hline $\mathrm{Z} 2$ & Pass & 400 (intermittent) & 7.1 & 6.2 \\
\hline
\end{tabular}

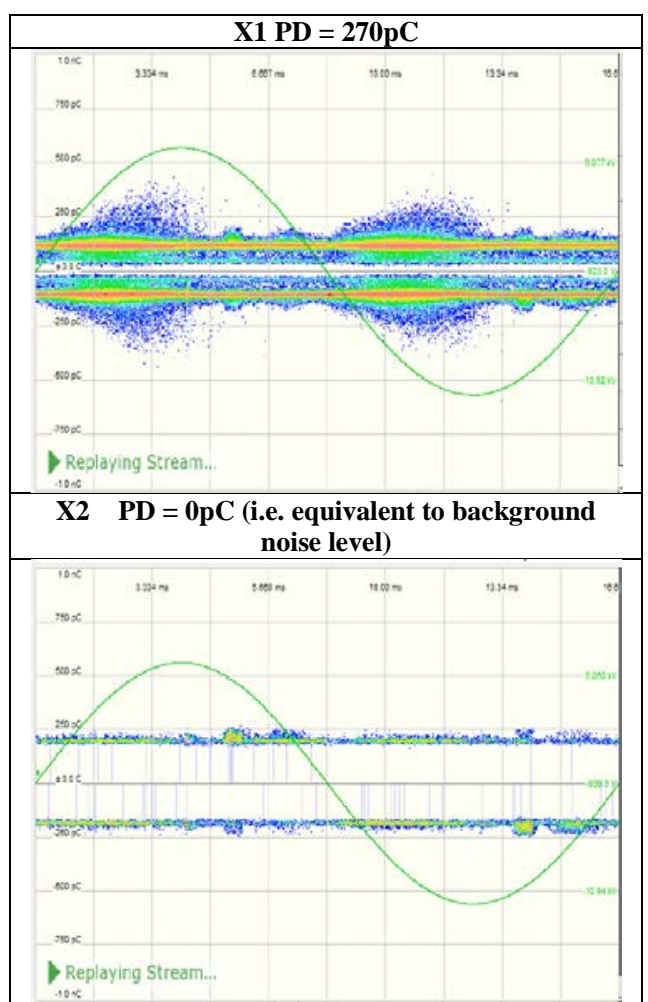

Figure 2: PRPD measured at $8 \mathrm{kV}$ for phases $\mathrm{X} 1, \mathrm{X} 2$ (data shown for IEC 60270 bandwidth)
The PD results from this case show that on all phases excluding Y2, the magnitudes and PDIV/PDEV levels were within reasonable tolerance to levels measured originally.



Figure 3: PRPD measured at $8 \mathrm{kV}$ for phases Y1, Y2 (data shown for IEC 60270 bandwidth)

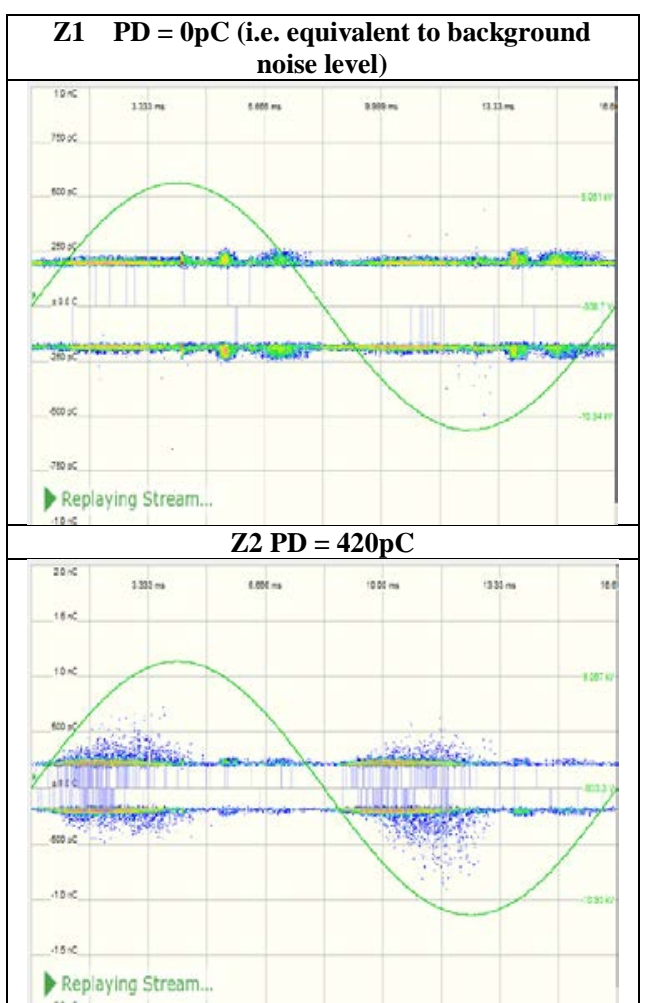

Figure 4: PRPD measured at $8 \mathrm{kV}$ for phases Z1, Z2 (data shown for IEC 60270 bandwidth) 
For the Y2 phase, PD magnitudes were significantly higher $(\sim 18 \mathrm{x})$ relative to data obtained 5 years prior. These results strongly suggested that a deterioration trend was present on this phase. Using a combination of ultrasonic probing, distributed broadband PD and TDR analysis, the source was localized to a single PILC termination. Based on this finding utility staff dissected and confirmed the presence of a defective connector and internal arcing in the suspect termination.

FDS testing was performed on each cable using a Megger IDAX 300 with applied voltage of $140 \mathrm{~V}_{\text {rms }}$. Figure 5 shows the test result. The tan delta minima lay within the range of $2.3 \times 10^{-3}-2.6 \times 10^{-3}$, suggesting that the bulk oil-paper insulation system was free from potentially damaging high moisture content and in good condition according the limits specified in Table 1.

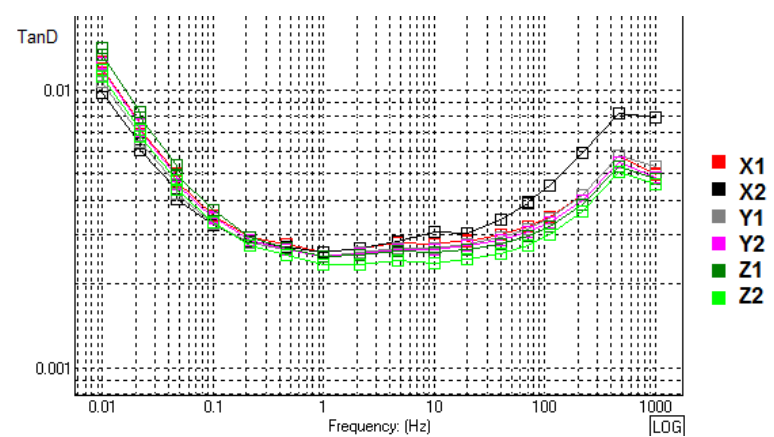

Figure 5: FDS measured at 140Vrms

\subsection{Transmission Class SCFF Cable}

Condition assessment using off-line AC PD and FDS was performed on $5,115 \mathrm{kV}$ SCFF cable circuits, ranging from 47 - 64 years age. Figure 6 and Table 4 show that Phase A of one 64 year old SCFF cable circuit exhibited a minimum loss factor FDS result of 0.0051 , which placed it just in the range of considerably aged/moist condition assessment, according to the assessment criteria in Table 1 . The minimum loss factor for associated phases B and C was 0.0039 , which placed it just in the range of a 'moderately aged/moist' condition assessment. Figure 6 shows that despite the seemingly small magnitude difference in the minimum loss factor between Phases A and B/C ( 0.1\%), this difference corresponded to a significant offset in the low frequency dielectric loss response (i.e. between 0.01 to $10 \mathrm{~Hz}$ ) which clearly distinguishes Phase A.

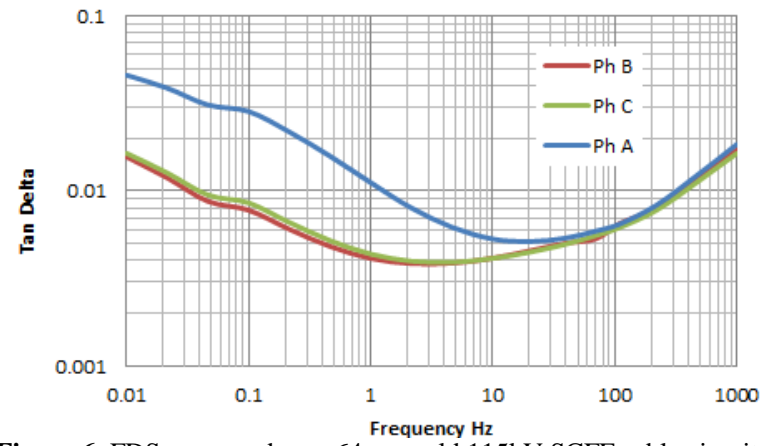

Figure 6: FDS measured on a 64 year old 115kV SCFF cable circuit
Table 4: Summary of FDS test results for a 64 year old 115kV SCFF cable (results correspond to Figure 6)

\begin{tabular}{|c|c|c|}
\hline Cable & $\begin{array}{c}\text { Minimum } \\
\text { PF }\end{array}$ & $\begin{array}{c}\text { Condition } \\
\text { assessment }\end{array}$ \\
\hline A phase & 0.00513 & Considerably aged \\
\hline B phase & 0.00384 & Moderately aged \\
\hline C phase & 0.00390 & Moderately aged \\
\hline
\end{tabular}

Figure 7 and Table 5 show results from off-line PD testing of another 58 year old SCFF cable circuit. In this case a high voltage variable frequency resonant test set was used to apply a test voltage of $66 \mathrm{kV}$, corresponding to $\mathrm{U}_{0}$, for approximately 10 minutes. The test voltage was then ramped up to $80 \mathrm{kV}$ corresponding to $1.2 \mathrm{U}_{0}$ and held for approximately another 10 minutes to allow for a PD measurement to be performed. PD data was acquired using HFCT sensors installed around the bonding cable at each of the terminations. The test frequency was $71 \mathrm{~Hz}$. The PD test was conducted not only at IEC 60270 bandwidth but also at higher frequency ranges.

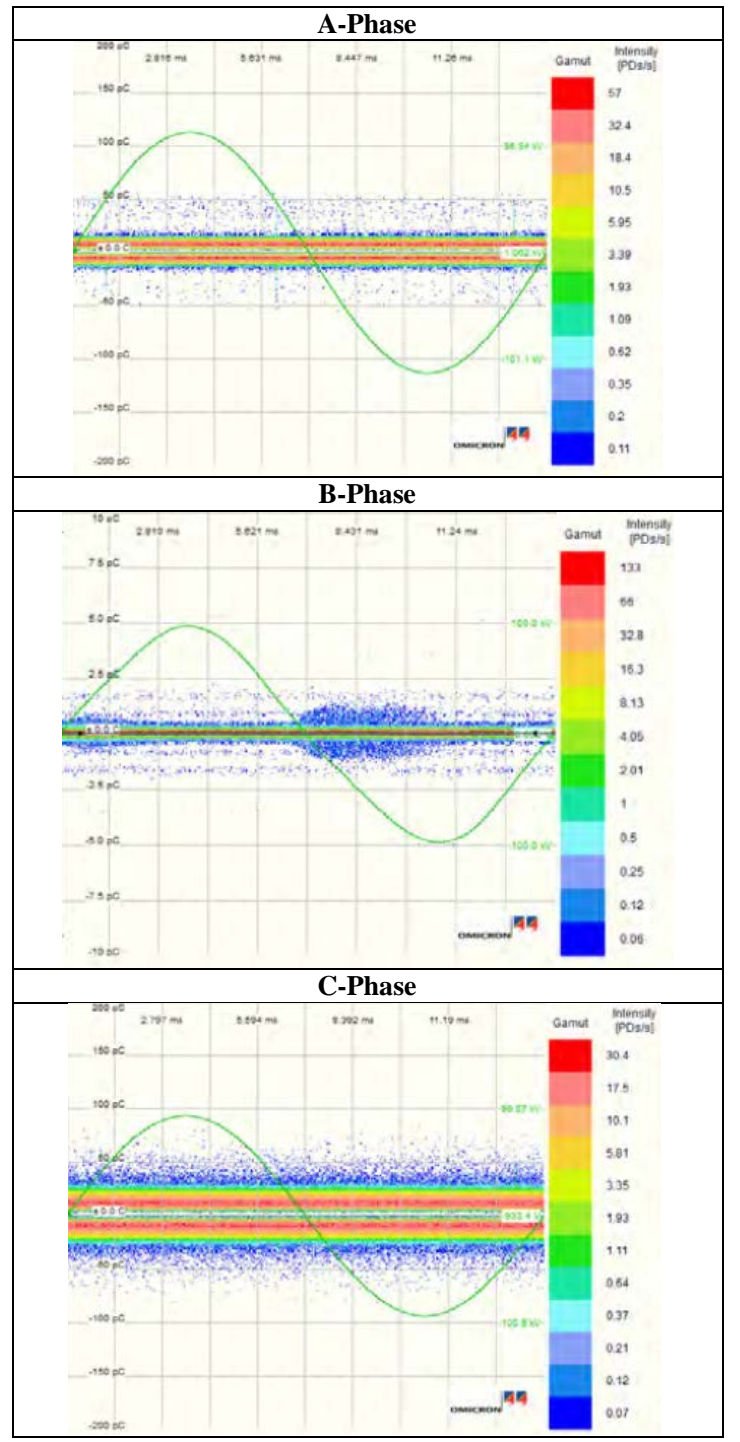

Figure 7: PRPD measured on a 58 year old $115 \mathrm{kV}$ SCFF cable circuit - measurements at $66 \mathrm{kV}, \mathrm{fc}=4 \mathrm{MHz}, \mathrm{BW}=1 \mathrm{MHz}$ 
Table 5: Off-line AC Hipot and PD test results from a 58 year old 115kV SCFF cable circuit, results correspond to Figure 7.

\begin{tabular}{|c|c|c|c|}
\hline $\begin{array}{c}\text { Phase } \\
\text { (Cable } \\
\text { ID) }\end{array}$ & $\begin{array}{c}\text { AC Hi-Pot } \\
\mathbf{- 8 0 k V} \text { for } \\
\mathbf{1 0} \text { Minutes }\end{array}$ & $\begin{array}{c}\text { PDIV } \\
(\mathbf{k V})\end{array}$ & $\begin{array}{c}\text { PDEV } \\
\mathbf{( k V )}\end{array}$ \\
\hline A & Pass & Above 80 & Above 80 \\
\hline B & Pass & 57 & 40 \\
\hline C & Pass & Above 80 & Above 80 \\
\hline
\end{tabular}

Figure 7 and Table 5 show that A-phase and C-phase of this $115 \mathrm{kV}$ SCFF circuit did not exhibit any PD patterns at the test levels. Signs of dielectric PD were, however, detected at the frequency range of $4 \mathrm{MHz}$ and higher for B-phase. Table 5 furthermore shows that the PD source in Phase B, as measured using broadband techniques, is active under operational stress since the PDEV is less than the rated line-ground voltage for the B-phase cable.

\section{Conclusions}

Focusing on off-line on-site electrical diagnostics, this paper presents the merits of using a technical approach, including acceptance criteria options, for in-situ field condition assessment of MV PILC and HV SCFF fluidfilled cables. Case studies presented show the benefits of utilizing a combination of AC Hipot testing, off-line PD, and frequency domain dielectric spectroscopy (FDS) testing for diagnostics and insulation condition assessment of fluid-filled cables.

Although off-line PD field diagnostics are reasonably well understood due to their wide-spread application in extruded cables, there are unique aspects in the PD based condition assessment of oil-paper insulated cables. For example; the possibility to rely on a trending based approach (arising from the more 'tolerable' nature of PD in oil-paper insulation systems), the influence of high frequency attenuation characteristics of oil-paper insulation on PD measurements, and the effects of duration between cable de-energization and testing on PD characteristics.

With respect to FDS it is noted that its application towards field aged fluid-filled cables is a more recent diagnostic technique, in comparison to the established use of dissipation factor measurements in advanced insulation diagnostics for other oil-paper insulated equipment (i.e. power transformers and bushings). It is thus recommended that a concerted effort be made amongst fluid filled cable interest groups to obtain DS (time domain or frequency domain) field and laboratory test data from a range of fluid filled cables both inservice and de-commissioned, of varying designs (SCFF, HPFF, MV PILC). Such a repository of knowledge will increase the accuracy of assessments of moisture content/qualitative aging in fluid-filled cable dielectric systems.

\section{References}

[1] Electra no. 176, Diagnostic methods for HV paper cables and accessories, 1998.

[2] IEEE Std. 1406-1998, IEEE Trial-Use Guide to the Use of Gas-In-Fluid Analysis for Electric Power Cable Systems.

[3] IEEE Std 1425 ${ }^{\mathrm{TM}}-2001$, IEEE Guide for the Evaluation of the Remaining Life of Impregnated Paper-Insulated Transmission Cable Systems

[4] IEEE 400.1-2007, IEEE Guide for Field Testing of Laminated Dielectric, Shielded Power Cable Systems Rated $5 \mathrm{kV}$ and Above with High Direct Current Voltage.

[5] CIGRE WG* $\mathrm{N}^{\circ}$ D1.34, Condition Assessment for Self-Contained Oil-Impregnated Insulation used in AC cables.

[6] IEC 60141-1, Part 1: Fluid-Filled, Paper or Polypropylene Paper Laminate Insulated, MetalSheathed Cables and Accessories for Alternating Voltages up to and Including $500 \mathrm{kV}, 1998$.

[7] IEEE Std 400.3-2006, IEEE Guide for Partial Discharge Testing of Shielded Power Cable Systems in a Field Environment.

[8] Ontario Hydro Standard STD5-C-H-57100-0012 R0, "Acceptance and Maintenance Testing of Cable Systems”, 1987.

[9] Y. Kita, N. Koizumi, "Remarks on the Hamon Approximation," Advances in Molecular Relaxation Processes, Vol. 7, Issue 1, pp. 13-20, 1975.

[10] Petri Hyvönen, PhD Thesis, "Prediction of Insulated Degradation of Distribution Power Cables Based on Chemical and Electrical measurements”, Helsinki University of Technology, 2008.

[11] R. Neimanis and R. Eriksson, "Diagnosis of Moisture in Oil/Paper Distribution Cables - Part I: Estimation of Moisture Content using FrequencyDomain Spectroscopy," IEEE Transactions on Power Delivery, vol. 19, pp. 9 - 14, Jan. 2004.

[12] S.Cherukupalli, V.Buchholz, M.Colwell, , JP.Crine, R.J.Keefer, "Condition Assessment of Distribution PILC cables from Electrical, Chemical and Dielectric Measurements”, IEEE Electrical Insulation Magazine. July/August 2004. Vol. 20, No. 4. pp 6-12

[13] Garton, C.G., "Dielectric Loss in Thin Films of Insulating Liquids," Electrical Engineers - Part I: General, Journal of the Institution of, vol.88, no.6, pp.245,248, June 1941.

[14] IEEE PC57.161 TM/D1.1, Draft Trial-Use Guide for Dielectric Frequency Response Test, March 2015.

[15] M. Gillespie, G. Murchie, G. Stone, "Experience with AC Hipot and PD Tests for Commissioning Generating Station Cables and Switchgear," IEEE Trans. on EC, Vol.4, No.3, pp. 392 - 396, 1989. 